\title{
Verification of a chamberless HLFC design with an outer skin of variable porosity
}

\author{
T. Kilian ${ }^{1}\left(\mathbb{D} \cdot\right.$ M. Horn ${ }^{2}$
}

Received: 30 July 2020 / Revised: 14 June 2021 / Accepted: 8 July 2021 / Published online: 28 August 2021

(C) The Author(s) 2021

\begin{abstract}
A chamberless HLFC leading edge segment featuring an outer skin with variable porosity has been designed, manufactured and wind tunnel tested under flight Reynolds-number conditions. The aerodynamic design involved the extention of current HLFC design routines to variable pressure loss characteristics of the outer skin. Advanced options for structural design and manufacturing solutions with focus on industrialization, arising from the avoidance of aerodynamically driven chambering, are explored. The leading edge segment has been installed on an existing vertical tail-plane model and tested at the large low-speed wind-tunnel facility DNW-LLF. The design process and some results of the successful verification of the chamberless design are presented herein.
\end{abstract}

Keywords Hybrid laminar flow control (HLFC) $\cdot$ Experimental aerodynamics $\cdot$ Manufacturing

\section{List of symbols}

A Pressure loss coefficient $\left(\mathrm{N} \times \mathrm{s} / \mathrm{m}^{3}\right)$

$B \quad$ Pressure loss coefficient $\left(\mathrm{N} \times \mathrm{s}^{2} / \mathrm{m}^{4}\right)$

$c_{Q} \quad$ Suction rate $w_{S} / U_{\infty}$

$c_{P} \quad$ Pressure coefficient

$P \quad$ Porosity

$U_{\infty} \quad$ Freestream velocity $(\mathrm{m} / \mathrm{s})$

$w_{S} \quad$ Suction velocity $(\mathrm{m} / \mathrm{s})$

$x / c_{\operatorname{Tr}} \quad$ Relative transition location

$\beta \quad$ Angle of sideslip (deg)

$\delta_{r} \quad$ Ruder deflection (deg)

$\Delta p_{\mathrm{SC}} \quad$ Pressure loss across suction skin $(\mathrm{Pa})$

\section{Introduction}

The ambitious goal of zero net carbon emissions in aviation until 2050, specified in the "European Green Deal", sets a highly challenging scene for the development of efficient and environmentally friendly future air transport vehicles.

T. Kilian

Thomas.Kilian@DLR.de

1 DLR German Aerospace Center, Institute of Aerodynamics and Flow Technology, Lilienthalplatz 7, 38108 Braunschweig, Germany

2 Institute of Structures and Design, Pfaffenwaldring 38-40, 70569 Stuttgart, Germany
Low-carbon kerosene alternatives, such as sustainable aviation fuels (SAF), liquified hydrogen or electrification, are emerging, yet offer less energy density and are currently much more cost intensive in production, storage and operation [1]. A significant reduction in energy consumption is, therefore, essential for the economical application of lowcarbon fuels to decarbonize aviation.

While there are multiple options to enhance energy efficiency in aviation, such as enhanced air traffic management and new propulsion concepts, laminar flow technology holds a large potential to reduce the aerodynamic friction drag by shifting the laminar-turbulent boundary layer transition further downstream and, thus, significantly reduces energy consumption during flight. Hybrid laminar flow control (HLFC) achieves the transition shift by both airfoil shape design as well as suction through a porous surface near the leading edge. The potential of the HLFC technology to realize a low-drag aircraft has been demonstrated on a large scale in the 1990s by heavily instrumented flight test campaigns featuring an Airbus A320 with a HLFC leading edge segment on the vertical tail plane [2] (Fig. 2) and also a Boeing 757 wing [3].

In the scope of the EU-funded project ALTTA ("Application of Laminar flow Technology on Transport Aircraft", 2000-2003), this concept has been further developed with regard to an increase of efficiency and a reduction of system complexity [4]. One major simplification of the so-called ALTTA concept, sketched in Fig. 1, is the introduction of 


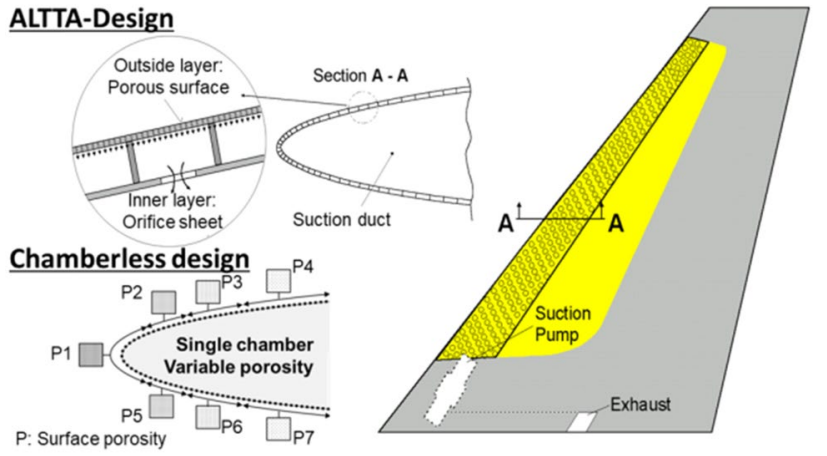

Fig. 1 Schematic view of the ALTTA and the chamberless HLFC concept [6]

one common suction duct. Rather than a formerly used complex multiple valve setup, which was far too heavy and occupied a large portion of the rear fuselage, the pressure within each suction chamber placed underneath the surface and the corresponding local mass flow is now adjusted by a combination of a constant surface porosity and throttle orifices, connecting it to this duct. This eliminates the necessity of active valves and most of the ducting and enhances the system's fail save operation capabilities. This systems functionality has been verified in the scope of the German LuFo ("Luftfahrtforschung") project versus ("Verifikation eines vereinfachten Absaugsystems", 2010-2015) by a windtunnel campaign at flight Reynolds numbers [5] as well as a recent flight test featuring an A320 HLFC fin within the European Union's 7th Framework Program project AFLoNext [6] (see Fig. 2). The acquired database proves the applicability of the large-scale wind tunnel results to flight conditions.

The ALTTA concept relies heavily on the variation of pressure levels across the chambers, making the complex task of sealing the chamber boundaries a vital necessity. To further increase the technology readiness level of HLFC and allow for an economical integration in an industrial environment, a chamberless or single-chamber HLFC design has been investigated in the scope of the LuFo funded project OptiHyL ("Optimization of Hybrid Laminarity", 2016-2019) amongst the partners DLR and Airbus. This novel design concept features an outer skin with areas of different porosity to achieve a desired suction velocity distribution without the use of chambers, as sketched in Fig. 1. It is expected to further lower the system complexity, manufacturing cost and quality management requirements. The DLR work-share was embedded in the project VarPorHyL ("Variable Porosität für Hybrid-Laminarisierung"). The goals are to design and manufacture an HLFC leading edge segment making use of a variable porous suction skin and to demonstrate its functionality in a large-scale wind-tunnel test, using vertical tail-plane model identical to the test performed in versus. In addition, fundamental and performance investigations of passive suction flaps for HLFC applications are to be performed.

In the scope of a UK nationally funded research project ARA has also recently wind-tunnel tested a small-scale HLFC wing with a suction skin of variable porosity. While the HLFC design concept and scientific goals were somewhat different here, the documented observations in [7] confirm the beneficial application of variable against constant porosity for HLFC suction skins.

\section{Aerodynamic design of a chamberless suction panel}

The aim of the aerodynamic design is to optimize a weighted cost function of laminar drag benefit (e.g., laminar extent) and required suction power, taking also structural requirements (see Sect. 3) into account. The vertical tail-plane (VTP) geometry used for this design is identical to the one used in versus [5]. A more detailed model description can be found in Sect. 5.1.The suction rates shall be in close coherence to allow for a direct comparison of design concepts.
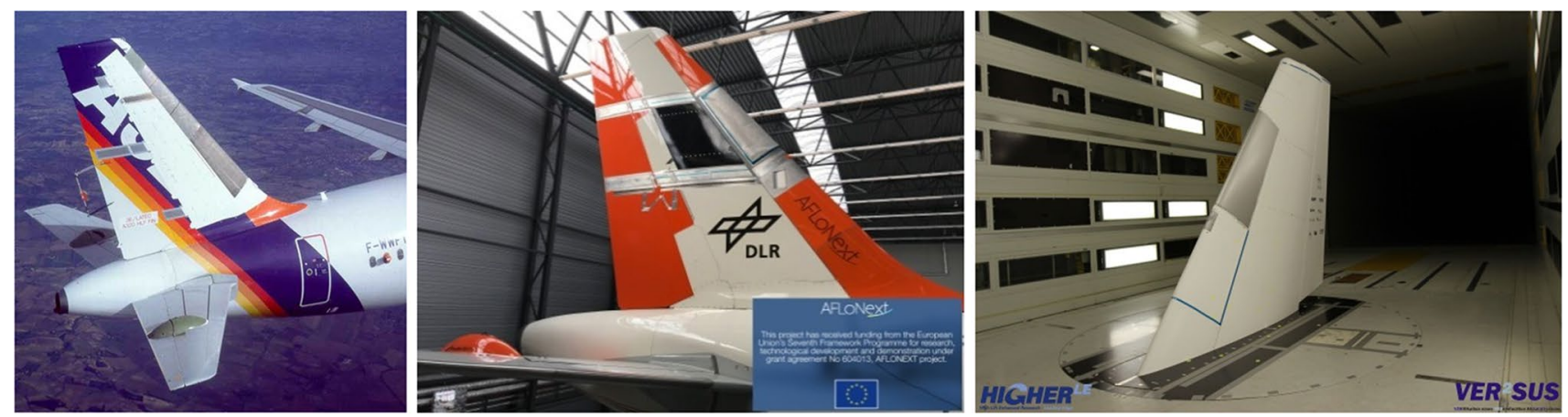

Fig. 2 Airbus' HLFC fin flight test (left) [4], the ALTTA system verification flight test within AFLoNext (middle) [6] and a wind-tunnel test of a VTP model at the DNW-LLF within VER ${ }^{2}$ SUS (right) [5] 


\subsection{Adaption of HLFC design process to variable porosity}

The DLR tool chain TASG [8] has been applied, which integrates the boundary layer analysis and transition prediction methods COCO [9] and LILO [10], as well as the suction chamber design program SCDP [11] by Schrauf into a semi-automated HLFC design and optimization process. While the boundary layer analysis and transition prediction routines of LILO were used without changes, the HLFC analysis of SCDP has been extended to suit the requirement of a variable pressure loss characteristic of the outer suction skin.

The quadratic relation between pressure loss $\Delta p_{\mathrm{SC}}$ and suction mean suction velocity $w_{\mathrm{S}}$ through the porous skin is described by the following equation and sketched in Fig. 3.

$\Delta p_{\mathrm{SC}}=A \times w_{S}+B \times w_{S}^{2}$,

with the pressure loss coefficients $A$ and $B$ being a function of the fluidic properties density and viscosity as well as the individual hole diameter, conicity, pitch and skin thickness.

While the ALTTA design uses only one curve, requiring a change of chamber pressure for suction velocity adaption, variable porosity allows for a plurality of curve parameters and with that a tailored relation between a global inner pressure and suction velocity.

Thus, for the chamberless concept, the suction chamber design is now replaced by a design of surface porosity to achieve the desired local suction rates at a given pressure drop over the suction skin applying Eq. 1.

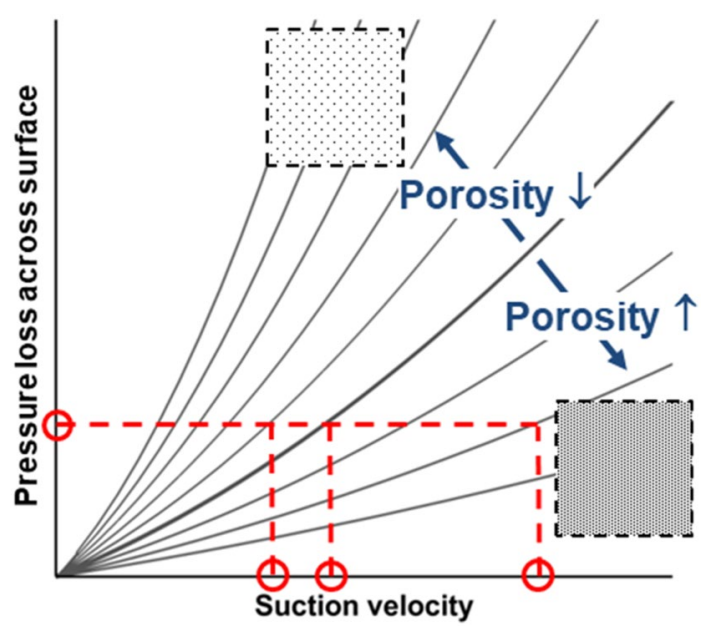

Fig. 3 Pressure loss characteristics curves

\subsection{Results of aerodynamic design}

The conditions for design were given at a freestream velocity of $U_{\infty}=100 \mathrm{~m} / \mathrm{s}$ and a mean chord Reynolds number of 23.3 Mio. The angle of sideslip $\beta$ as well as rudder deflection $\delta_{r}$ range from $+2^{\circ}$ to $-2^{\circ}$. The micro-perforation diameter was set to $55 \mu \mathrm{m}$, which is known to be the lower stable limit of the applied drilling process. To avoid adverse interaction of vortices, emanating from suction holes, the pitch needs to be larger than 10 times this diameter [12]. The upper pitch limit was chosen to $1300 \mu \mathrm{m}$, an order of magnitude below the expected blockage due to structural stiffeners, to avoid premature transition, should several holes in local flow direction be blocked. Furthermore, choking and additional aerodynamic roughness due to the over-suction phenomenon, introduced by Pfenninger [13], had to be avoided.

Simulation results for the chamberless ("VarPorHyL") and ALTTA ("VER ${ }^{2}$ SUS") design in Fig. 4 show the Tollmien-Schlichting (TS) and cross-flow (CF) amplification rates $\mathrm{N}$ along with the pressure distribution and the non-dimensionalized suction velocity $C_{Q}=W_{s} / U_{\infty}$ for a reference airfoil section at an angle of sideslip of $0^{\circ}$. The suction distributions include areas of blockage caused by stiffener elements attached to the surface. While those small no-suction areas as well as step changes in suction rate introduced by porosity changes do have a theoretical effect on the amplification rates, there has been no detrimental effects noticed in former unpublished studies up to a blocking length of $10 \mathrm{~mm}$ in streamwise direction. Yet special attention needs to be put on the design near the attachment line, to avoid attachment line transition (ALT) or strong undamped cross-flow amplifications.

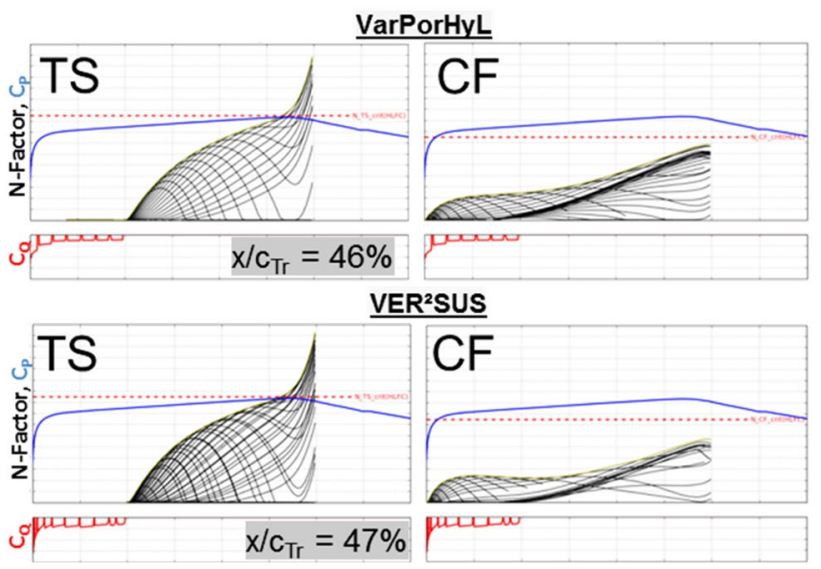

Fig. 4 Chord-wise suction and amplification rates from TASG simulations comparing the chamberless (upper, "VarPorHyL") to the ALTTA concept (lower, "VER ${ }^{2}$ SUS") 
For better comparison, Fig. 5 shows an enlarged comparison of the suction rates of both designs. Small deviations in suction level especially towards the rear do not significantly affect the amplifications. The advantage of the chamberless approach becomes apparent near the leading edge, where the ALTTA design requires a much closer staggering of chamber boundaries to realize the targeted suction rates at high outside pressure gradients. Amplifications are sufficiently damped by the applied suction and transition locations are in close coherence, which was one of the mayor design objectives.

\subsection{Structural design of suction segment}

As descripted above, the variable porosity of the outer skin leads to a partial separation of the structural and the aerodynamic dependence. To take advantage of the gained structural degree of freedom, some preliminary studies to optimize the inner structure were carried out. The goals of these studies were to simplify the manufacturing process and to reduce the weight penalty as much as possible, while maintaining the aerodynamic requirements. The very conservative surface waviness criteria by Carmichael [14] are the most important aspect to be considered here (Fig. 6).

The first study aimed at the general setup of stiffener elements on the inner side of the suction skin. Since there is no internal chambering, these elements may be regarded as simple spacers between outer skin and load carrying inner structure. The goal was to determine the setup with the best ratio of outer skin deformation to weight of the spacer. Thus, a simplified structure model, consisting of outer skin and variable spacer configuration, was set up. The considered load cases represent the envelope of expected HLFC operation. The following spacer setups were investigated, while the number of the spacers was also subject to variation:

- ribs, arranged in flow direction

- ribs, arranged perpendicular to leading edge

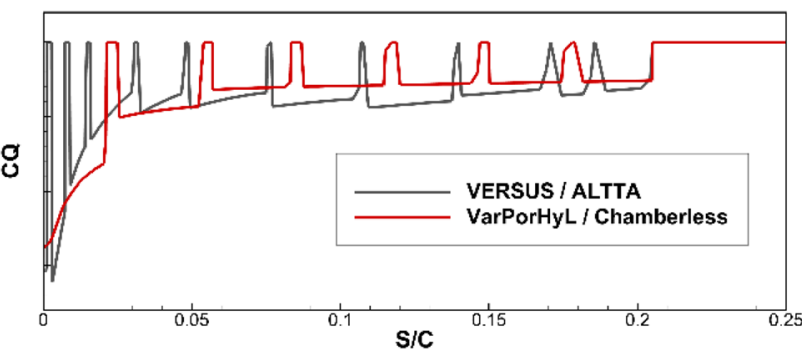

Fig. 5 Suction rates over chord for ALTTA and chamberless concept
- stringers, radially arranged

Figure 7 summarizes the studied stiffener setups. The number of stiffeners increases from left to right. Surfaces are color coded by deformation, with non-blue areas indicating medium to high deformations. In conclusion, all spacer concepts investigated here can successfully limit the skin deformation and, thus, fulfill the waviness criteria. Yet, the stringer setup shows the best ratio of deformation to number of spacers and was, therefore, chosen for the detailed design of the leading edge. It is also the one with the least suction blockage in line of flight, which is important for the successful damping of amplification rates in the flow (Table 1).

A second study to determine the most favorable shape of the inner structure was performed. For this study, five different designs were assessed similar to the spacer study:
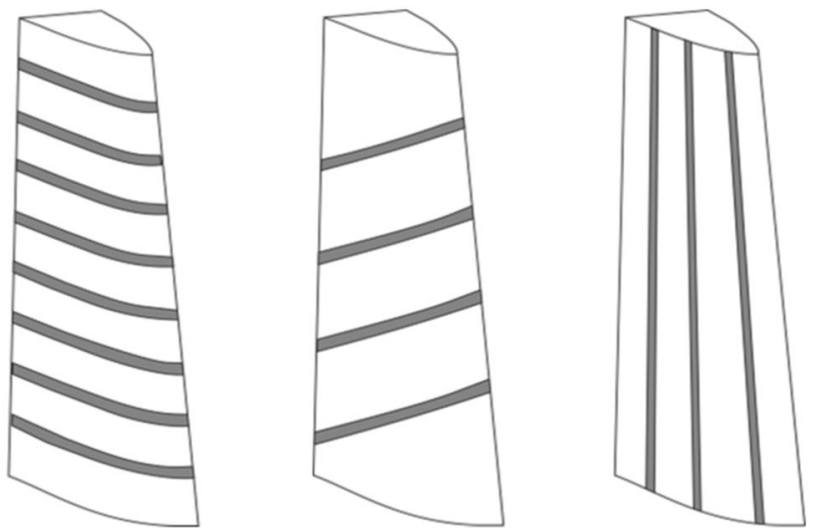

Fig. 6 Investigated spacer setups. Ribs in flow direction (left) and perpendicular to front spar (middle) and radial stringers (right)
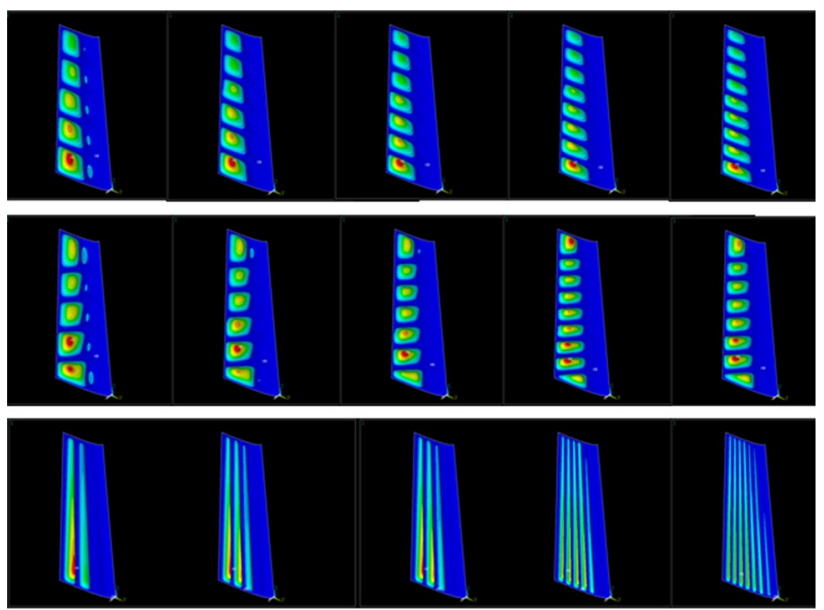

Fig. 7 Surface deformation of spacer variations. Color coding: blue (low) to red (over-critical) 
Table 1 Variations of inner structure geometry

\begin{tabular}{|c|c|c|c|c|c|}
\hline & Sharpe splitter & Folded splitter 1 & Folded splitter 2 & $\begin{array}{c}\text { Equidistant offset } \\
\text { (15 mm) }\end{array}$ & $\begin{array}{c}\text { Equidistant offset } \\
\text { (20 mm) }\end{array}$ \\
\hline Design & 0,38 & 0,42 & 0,49 & 0,45 & 0,40 \\
\hline $\begin{array}{c}\text { Weight [kg] } \\
\text { [mm] }\end{array}$ & 15,9 & 15,5 & 15,4 & 15,6 & 15,7 \\
\hline $\begin{array}{c}\text { Deformation* } \\
\text { weight } \\
\text { [mm kg] }\end{array}$ & 6,0 & 6,5 & 7,5 & 7,1 & 6,3 \\
\hline
\end{tabular}
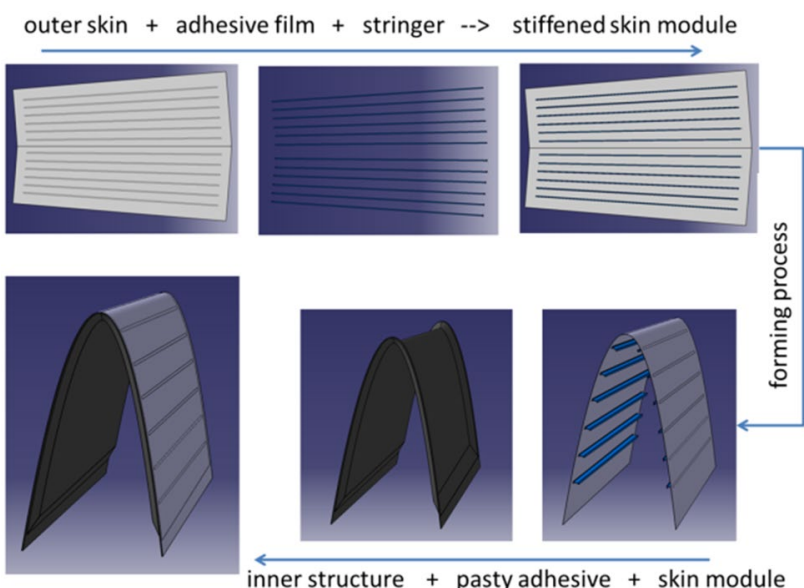

inner structure + pastyadhesive + skin module

Fig. 8 Leading edge manufacturing process

- sharp splitter shape for advanced bird strike integrity [15]

- folded splitter shape to reduce stringer height

- folded splitter shape for maximum reduction of stringer height

- equidistant inner shape with small offset

- equidistant inner shape with large offset

Conclusively, the sharp splitter leads to the smallest deformation and weight values. But as mentioned before, beside the structural behavior also industrialization aspects will be taken into consideration. Finally, the design with an equidistant shape and an offset of $20 \mathrm{~mm}$ was chosen, because its structural behavior is similar to the splitter's performance, but it offers the possibility to simplify the manufacturing by the use of common parts for the stringers. Furthermore, the use of stringers allows for the fixation onto the flat outer skin before forming the skin into the final leading edge shape. This simplifies the production and quality management process, since bonding can be easily

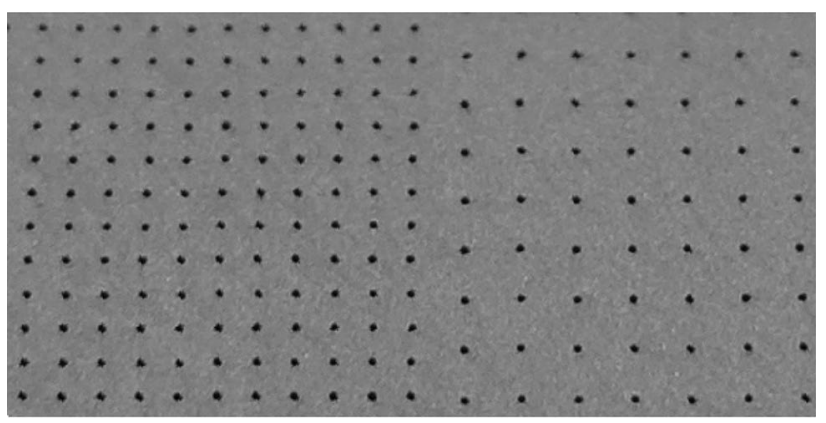

Fig. 9 Typical porosity variation

controlled and excessive micro-perforation blockage can be avoided (Fig. 8).

\subsection{Manufacturing of leading edge segment}

This chapter will give an overview over the leading edge manufacturing process with focus on the large, variable porous metallic sheets as well as a manufacturing quality assessment.

With the results of the preliminary studies and the mentioned simplifications for manufacturing, the following manufacturing process was developed:

\subsection{Micro-perforation of outer skin}

For the wind tunnel test, stainless steel was set as the material for the outer skin. However, the described process may be adapted to titanium for any in service applications. Furthermore, a single pulse laser drill process [5] was used for the micro-perforation.

To meet the requirements of a variable porous outer surface, the drill process was adapted to generate perforated surfaces with variable distances of the drill holes to realize defined pressure drop characteristics. Figure 9 shows a 
typical interface of areas with different bore hole distances (pitch) and, thus, pressure drops.

Since the chamberless concept implies, that the suction distribution along the leading edge is defined solely by the pressure drop of each perforation area and cannot be adjusted afterwards (e.g., by throttle holes), a meticulous quality management is mandatory. To determine the characteristics of the porous surface, a combination of pressure drop measurements and optical measurements seems to be suited best: the pressure drop measurement gives direct evidence about the most important property of the porous surface. The optical measurement using reflected and transmitted light microscopy is an important addition and delivers information about the uniformity of the drill hole distances, the degree of blockage of single drill holes and their geometrical properties (drill diameter laser entry/exit side, roundness)

DLR's laminar flow meter LFM [16] was used to measure the pressure loss characteristics of micro-perforated samples as well as the final skin with a very high accuracy. The results on coupon level depicted in Fig. 10 show the expected relation between porosity and pressure loss $\Delta P$ at a range of mean suction velocities $w_{s}$. The repeatability of results for three coupons per pitch (symbols) is generally high with the exception of one sample at a pitch of $700 \mu \mathrm{m}$, where the deburring process was slightly altered. This highlights the necessity for a stable, well-defined and constantly monitored micro-perforation process.

The general observations from optical measurements, using a Keyence VHX-7000 microscope, are in good accordance to the pressure loss results. Very little spread in bore hole distances in the order of $\pm 1 \mu \mathrm{m}$ and also an acceptable variation in hole diameter of under $5 \%$ are observed. Only the above-mentioned sample, produced with an altered deburring process, has an increased mean hole diameter and

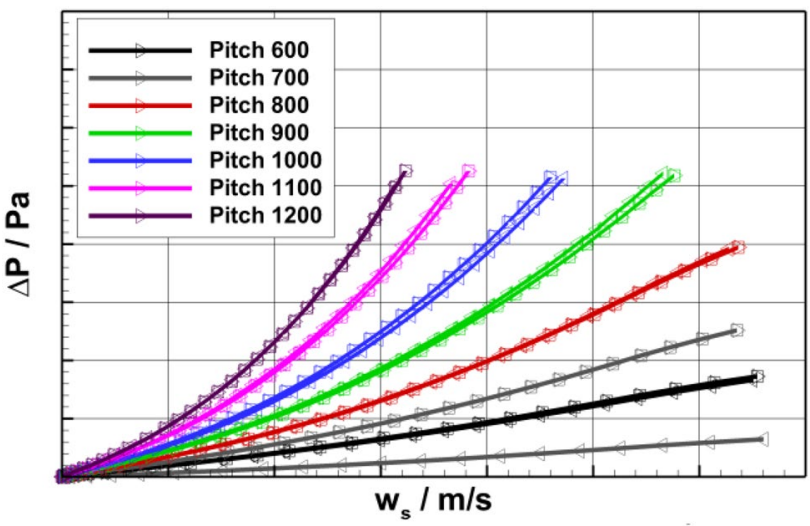

Fig. 10 Pressure drop measurements of samples with variable porosity. Three coupons per pitch (symbols) also shows larger variation within the sample. This coincides with the lower pressure loss measured by the LFM.

\subsection{Leading edge assembly}

The detailed structural design of the leading edge was performed based on the results of the mentioned aerodynamic and structural studies as well as experiences from VER ${ }^{2}$ SUS. The final assembly can be seen in Fig. 11 and consists of the metallic outer skin, the stringers, the inner structure and the sealing membrane. The inner structure is made of carbon fiber-reinforced plastic and designed as an integral structure. Beside its load carrying function, the inner structure builds the single chamber of the leading edge. The sealing

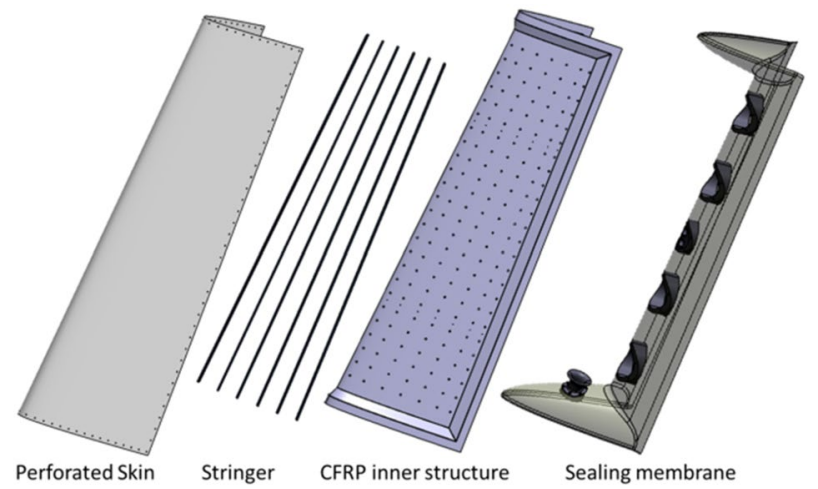

Fig. 11 Assembly of leading edge segment

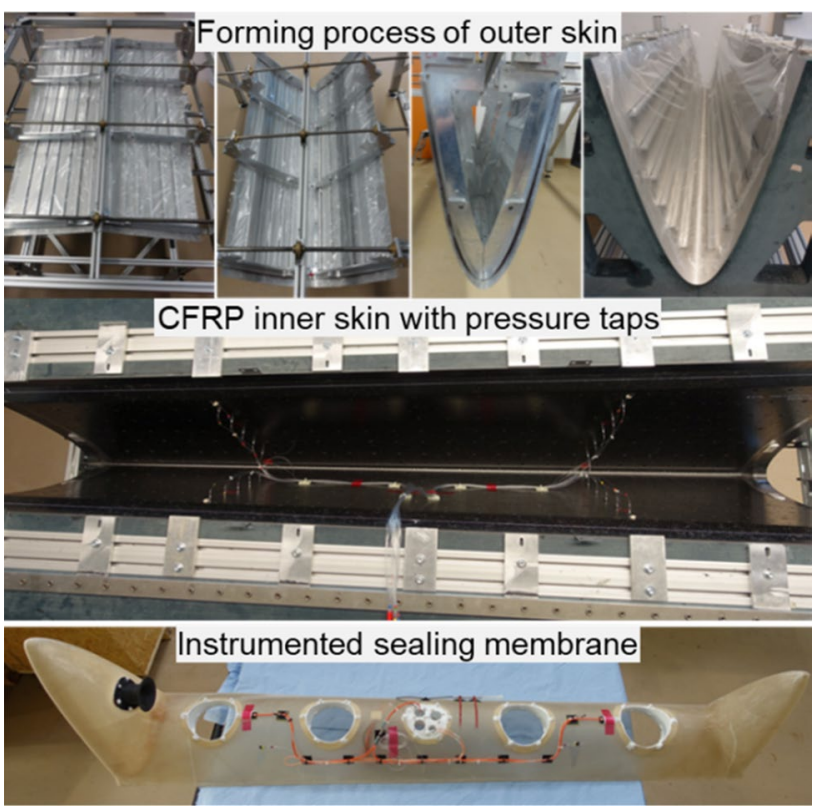

Fig. 12 Manufacturing process of the outer skin, the inner structure and the sealing membrane 
membrane closes the evacuated volume and is equipped with the suction exhaust, sensor ducts and service openings.

The manufacturing of the wind-tunnel demonstrator, shown in Fig. 12, was done with proven tools and devices of the VER ${ }^{2}$ SUS project [5], which were adapted to the new leading edge design. The stringers are bonded to the outer skin, which is then formed into its final shape and inserted into a mould. Inner structure and sealing membrane are then subsequently bonded.

To verify the manufactured leading edge segment, the finalized part was 3D-scanned in build-in condition and compared to the CAD shape (Fig. 13).

The deviations of the leading edge segment with a length of $2.0 \mathrm{~m}$ are in a range of $\pm 0.20 \mathrm{~mm}$ and local waviness is below the limits by Carmichael. In conclusion, the manufacturing process leads, notwithstanding to some fundamental simplifications, to a high geometrical accuracy and is, thus, suitable for laminar applications.

\subsection{Wind-tunnel test setup}

The large low-speed facility (LLF), operated by the German-Dutch Wind-Tunnels Foundation DNW, is an atmospheric closed return circuit wind tunnel for industrial aerodynamic and aero-acoustic testing of complete aircraft configurations or its components. It can be operated with several interchangeable open and closed test sections. Due to the model size and Reynolds-number requirements the 6 $\times 8 \mathrm{~m}$ closed test section was used with the model attached

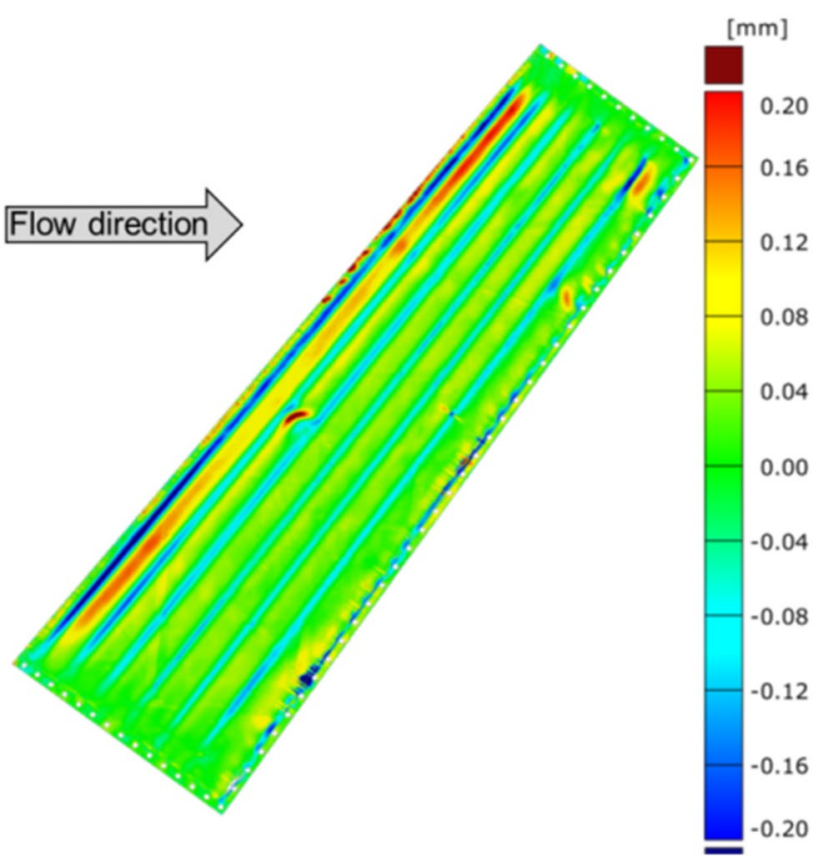

Fig. 13 Surface measurement of wind-tunnel demonstrator

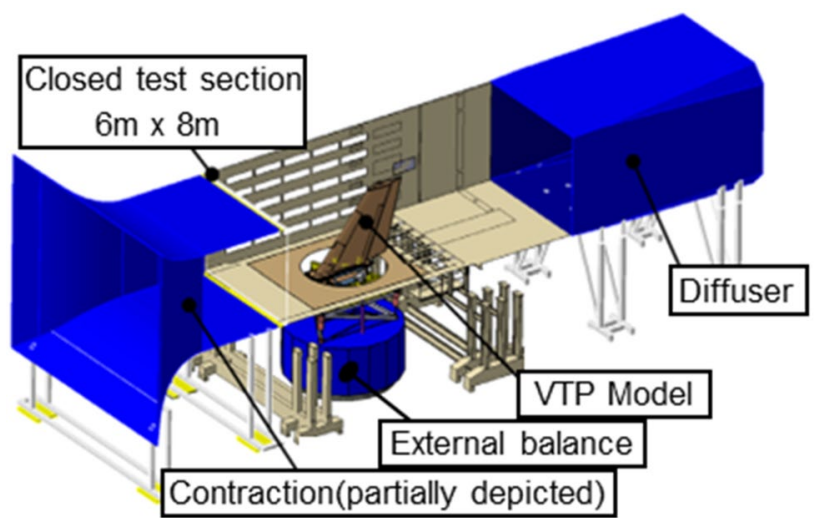

Fig. 14 DNW-LLF $6 \times 8 \mathrm{~m}$ closed test section including VTP model

to a rotatable platform balance underneath the test section floor (Fig. 14).

\subsection{The VER ${ }^{2}$ SUS replacement fin with chamberless HLFC leading edge segment}

The model of a vertical tail plane was originally designed and manufactured in the scope of the project VER ${ }^{2}$ SUS [5]. The geometry is closely derived from an Airbus A320 fin. The span has been cropped to $4.5 \mathrm{~m}$ to minimize test section blockage and the airfoil geometry is redesigned to match the pressure distribution of the full size fin in transonic cruise conditions. Special focus was put on the pressure gradient across the rear end of the suction panel, which largely affects the amplification of flow instabilities and with it the transition location. The model's leading edge sweep is at $40.38^{\circ}$.

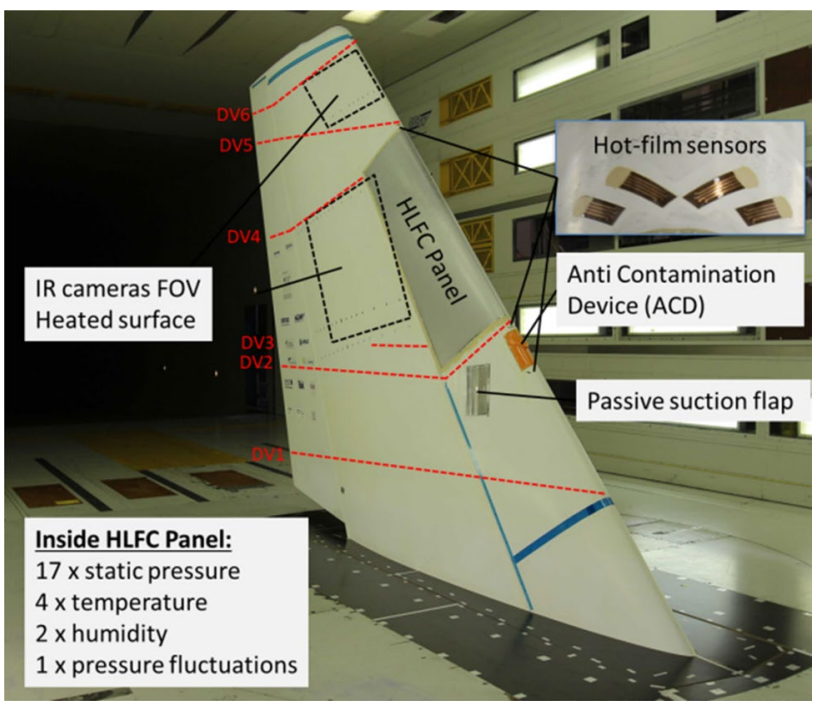

Fig. 15 Model setup inside the test section and instrumentation overview 


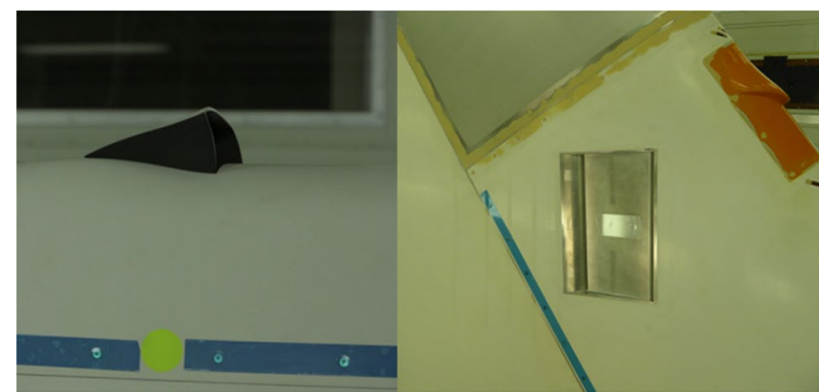

Fig. 16 Passive suction flaps of 2014 (left) and 2018 (right) test

Figure 15 gives an overview of the instrumentation. The model is equipped with 510 surface pressure taps distributed along six rows (DV1-6). 10 hot-film sensors at the leading edge detect attachment line transition (ALT) above and below the HLFC panel. For the testpoints discussed herein, an anti-contamination device was installed to avoid just this mode of transition. Infrared thermography was used to measure surface temperatures behind the HLFC panel and in an additional NLF (natural laminar flow) area, visualizing the transition from laminar to turbulent boundary layer state. Four infrared cameras and surface-embedded heat mats are used for that purpose. The surface flow topology was visualized using tufts.

The suction nose itself is also highly instrumented with multiple sensors distributed along the interior structure measuring static pressure, temperature, humidity as well as pressure fluctuations (Fig. 16).

\subsection{Redesigned passive suction flap}

A passive suction flap deflecting from the surface and connected to the HLFC segment via internal ducts may aid or even replace a compressor, making the system more lean and efficient. Its working principle is based on a combination of placement inside a low pressure region and a nozzle effect through the flow passing over it.

In the 2014 test campaign, a passive suction flap was integrated at the VTP tip. It was mainly designed by DLR to explore the possibility to passively operate an HLFC system. The results shall also serve as validation database for CFD-aided simulation tools. However, spatial restrictions at the tip and long piping limited the performance of this flap.

In the scope of the project AFLoNext, a more advanced flap placed near the leading edge underneath the suction panel has been designed [17] and flight tested [6]. Although this flap is designed for high subsonic Mach numbers, the general principle of operation does not change to low speed, only the flaps efficiency increases [18]. The same flap geometry was, therefore, also integrated into the VER ${ }^{2}$ SUS VTP model.

\subsection{Results of wind-tunnel test}

The results presented hereafter are a short summary of the extensive database created during 7 days of wind-tunnel measurements. The main focus of this work is to demonstrate the HLFC capabilities of the chamberless concept, including active (compressor) and passive (suction flap) operation.

To assure a profound and meaningful comparison of HLFC capabilities of the chamberless to the reference design, a long-term repeatability study between the two test campaigns in 2014 and 2018 was performed. Figure 17 shows a good match of surface pressure distributions at two sections along the span at two angles of sideslip $0^{\circ}$ and $2^{\circ}$. A comparison of the two concepts based on the measured values may, therefore, be regarded as justified.

\subsection{Active HLFC operation with compressor system}

Having established the reproducibility of aerodynamic flow conditions across test entries, comparisons of the chamberless to the ALTTA concept may be drawn from the laminar extend under HLFC operation. A visualization of laminar extent using infrared thermography with and without HLFC operation is shown in Fig. 18. Tickmarks on the surface allow for the determination of the chord-wise transition location. While the conditions are fully turbulent without suction, both concepts show a very similar laminar extent. The spiky transition line indicates a coupled cross-flow and Tollmien-Schlichting waves induced transition, in accordance with the simulations. Turbulent wedges result from surface imperfections upstream on the HLFC panel or at the interface to the wing-box. The maximum achieved laminar extends are shown, limited by the geometrical airfoil shape
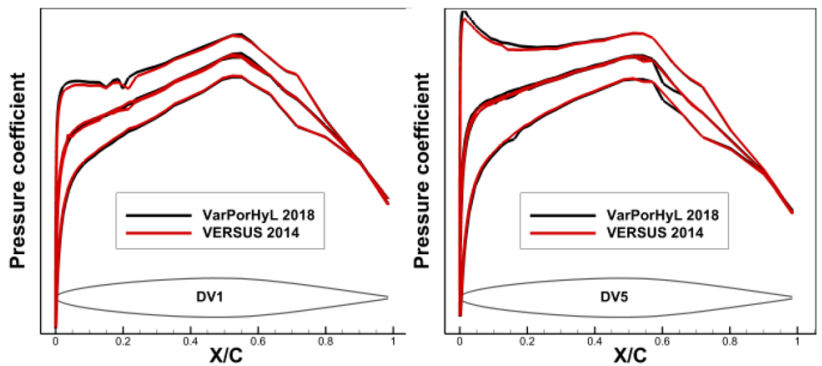

Fig. 17 Comparison of surface pressure at two airfoil sections below (left) and above (right) the HLFC panel between the wind-tunnel test in 2014 and 2018 


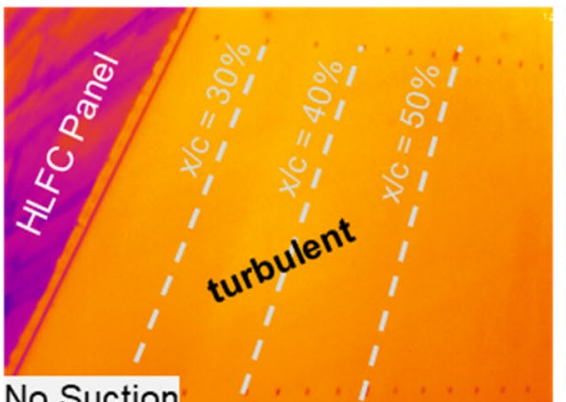

No Suction

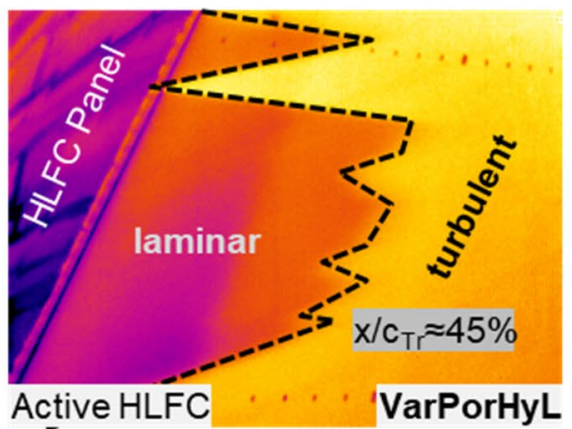

Active HLFC

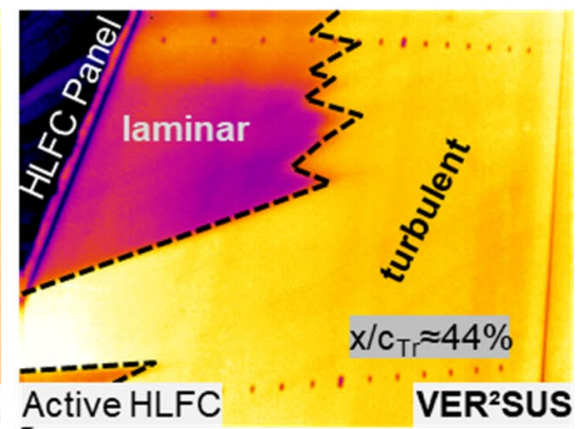

Fig. 18 Boundary layer state (laminar/turbulent) visualization with and without HLFC operation comparing the chamberless ("VarPoHyL") to the ALTTA ("VER ${ }^{2}$ SUS") concept. Flow direction from left to right

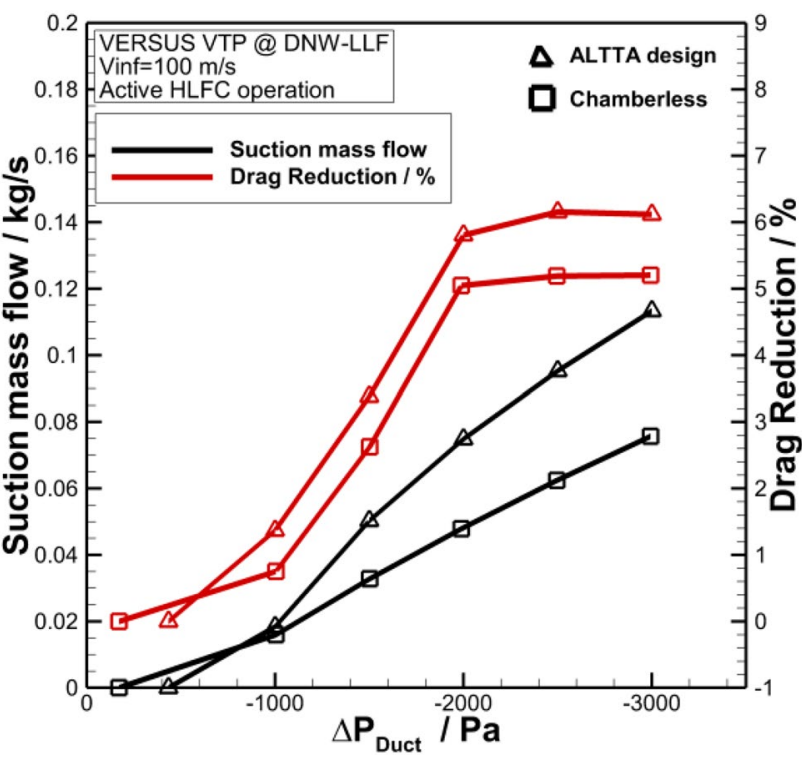

Fig. 19 Mass flow through HLFC system, relative duct pressure and drag reduction for active HLFC operation. Comparison of ALTTA and chamberless design

and not further extendable by suction increase. This saturation becomes apparent from the decreasing drag reduction gradient at higher suction levels. Figure 19 shows a linear relationship between suction mass flow and the relative duct pressure $\Delta P_{\text {Duct }}=P_{\text {Duct }}-P_{\text {inf }}$, while the drag reduction levels out at around $5 \%$ of the total model drag. This correlates with the state of maximum laminar extent in the infrared images. Due to turbulent wedges caused by surface imperfections, the relative drag reduction level is reduced. This also explains the offset between the two design concepts.

The duct pressure levels to reach the depicted state in Fig. 18 are in close coherence for both design concepts, which leads to the conclusion, that they share a similar net HLFC performance. Differences in mass flow levels are due to a slightly more conservative suction design for the

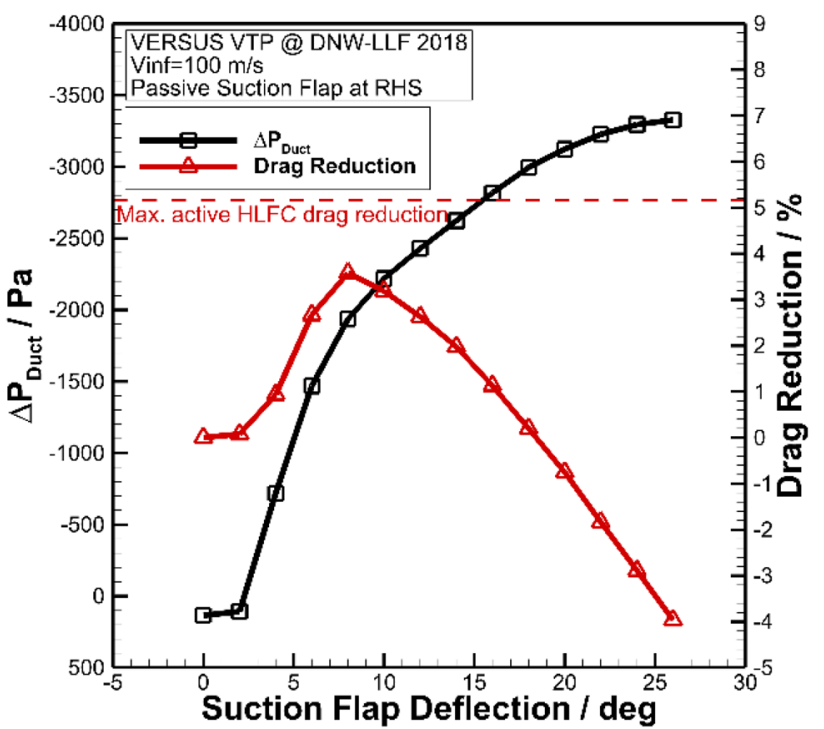

Fig. 20 Relative duct pressure and drag reduction for passive HLFC operation

ALTTA concept and are not an inherent advantage of the chamberless design.

The observed transition locations are in very good agreement to the simulation results (Fig. 4). The marginal offsets visible for both designs are known to be in the order of the systematic uncertainties of the applied measurement techniques and simulation tools. This may serve as a validation of the performed adaptation of the TASG tool chain to HLFC design including variable pressure loss characteristics of the outer suction skin.

\subsection{Passive HLFC operation with suction flap}

Figure 20 shows the relation between suction flap deflection, relative duct pressure and overall drag force. As learned from Fig. 19, there is a mostly linear relation between duct pressure and suction mass flow. 
Growing flow separations downstream of the flap noticeably decrease its effectiveness towards higher deflection angles. At the same time, the deflection-related drag continuously increases, leading to an efficiency peak and sensible point of operation at around $8^{\circ}$ of deflection. According to the achieved duct pressure levels, the transition shift is comparable to the one with active HLFC operation. The difference in drag reduction relative to an active operation is caused by the deflection-related drag, while a compressor power drag equivalent is not considered yet. The refinement of the drag breakdown for active and passive HLFC operation is part of an ongoing research activity.

\subsection{Summary and outlook}

A chamberless HLFC leading edge segment featuring an outer skin with variable porosity has been designed, manufactured and wind tunnel tested under flight Reynoldsnumber conditions.

The aerodynamic design process has successfully been adapted to variable pressure loss characteristics of the outer skin. The chamberless concept provides additional structural design options, which have been explored. A combination of an equidistant inner shape and stringers has proven to be the most advantageous option regarding structural integrity, deformation and industrialization.

The design was verified in a large-scale wind-tunnel test. Laminar extent, drag reduction and power consumption are comparable to the state-of-the-art ALTTA design. The HLFC system may also be equally operated using a newly designed passive suction flap, with a slightly lowered drag benefit due to flap deflection drag. For a more thorough comparison of active and passive HLFC operation, a more detailed drag assessment of both concepts has to be performed, which is part of an ongoing research activity.

Due to the lack of throttle holes for final suction adjustments, even more focus has to be put on the manufacturing quality of the micro-perforated sheets. Key to a performant chamberless HLFC system is, therefore, a stable and reproducible process for micro-perforation including deburring and in-the-loop quality monitoring. There are currently some efforts made to industrialize this process [19].

Further ongoing research activities in Clean Sky 2 focus on the development and demonstration of other variable porosity suction surface concepts using innovative skin layouts like TSSD (tailored skin single duct). The TSSD concept is based on a multi-layered tailored outer skin with an intrinsic pressure drop distribution [20,21], which may help to circumvent some of the quality management issues currently linked to the micro-perforation process.
Acknowledgements The project VarPorHyL has received funding by the German Federal Ministry for Economic Affairs and Energy under the "Luftfahrtforschungsprogramm" LuFo V-2, contract numbers 20A1501C

Funding Open Access funding enabled and organized by Projekt DEAL.

Open Access This article is licensed under a Creative Commons Attribution 4.0 International License, which permits use, sharing, adaptation, distribution and reproduction in any medium or format, as long as you give appropriate credit to the original author(s) and the source, provide a link to the Creative Commons licence, and indicate if changes were made. The images or other third party material in this article are included in the article's Creative Commons licence, unless indicated otherwise in a credit line to the material. If material is not included in the article's Creative Commons licence and your intended use is not permitted by statutory regulation or exceeds the permitted use, you will need to obtain permission directly from the copyright holder. To view a copy of this licence, visit http://creativecommons.org/licenses/by/4.0/.

\section{References}

1. Bauen, A., Bitossi, N., German, L., Harris, A., Leow, K.: Sustainable aviation fuels. Johns. Matthey Technol. Rev. 64(3), 263-278 (2020)

2. Henke, R.: The Airbus A320 HLF Fin Programme. Nouvelle Revue d'Aeronautique et d'Astronautique 2, 53-55 (1998)

3. Joselin, R.: Overview of Laminar Flow Control. NASA/ TP-1998-208705. Hampton, Virginia (1998)

4. Horstmann, K.-H., Schrauf, G., Sawyers, D., Sturm, H.: Simplified suction system for a HLFC leading edge box of an A320 fin. In: CEAS Aerospace Aerodynamics Research Conference, Cambridge (2006)

5. Horn, M., von FrhrGeyr, H., Weddig, T., Bruns, J., Schradick, M.: Auslegung, Fertigung und Funktionsdemonstration einer HLFC Leading Edge, in DLRK 2016. Braunschweig, Germany (2016)

6. Schrauf, G., von Geyr, H.: Simplified Hybrid Laminar Flow Control for the A320 Fin Aerodynamic and System Design First Results, in AIAA Science and Technology Forum and Exhibition - SCITECH. Orlando, Florida (2020)

7. Ciarella, A., Lawson, S., Wong, P.: Aerodynamic and Transition Analysis of the Hybrid Laminar Flow Control Wing Experiment at the ARA Wind Tunnel, in AIAA Aviation 2019 Forum. Dallas, Texas (2019)

8. Streit, T., Wedler, S., Kruse, M.: Natural and Hybrid Laminar Wing Design Incorporating New Methodologies in the Aeronautical Journal, pp. 1303-1326. Cambridge University Press (2015)

9. Schrauf, G.: COCO - A Program to Compute Velocity and Temperature Profiles for Local and Nonlocal Stability Analysis of Compressible, Conical Boundary Layers with Suction. ZARM Technik Report, Bremen, Germany (1998)

10. Schrauf, G.: LILO 2.1 - User's Guide and Tutorial. Technical Report, GSSC 6, Bremen, Germany (2006)

11. Schrauf, G.: SCDP - A Suction Chamber Design Program - Version 1.4. Technical Report, GSSC TR 8.4, Bremen, Germany (2013)

12. MacManus, D.G.: An Aerodynamic Prediction Technique for Laminar Flow Control Suction Surfaces. Dissertation, Department of Mechanical Engineering, University College Galway (1996) 
13. NASA, 1999 High Reynolds Number Hybrid Laminar Flow Control (HLFC) Flight Experiment. Report 2, Aerodynamic Design, NASA/CR-1999-209324

14. Carmichael, B.H.: Surface Waviness Criteria for Swept and Unswept Laminar Suction Wings. Northrop Aircraft Report No. NOR-59-438 (1957)

15. Ritt, S.A., Schneider, M.: Structural design for hybrid laminar flow control to toughen up the laminar technology. In: DLRK 2016, München, Germany (2016)

16. Seitz, A.: Messkörper, Durchflussmesssystem und Computerprogramm dafür (Patent pending). Patent 202014104 037, 04. 12. (2015)

17. Bauer, M.: Parametrische Untersuchung der Geometrie einer passiven Absaugung für HLFC-Systeme. Technical University of Braunschweig, Studienarbeit (2016)

18. Kilian, T., Krause, U., Schaber, S., Neufeld, D.: Validation experiment on a passive suction flap for Hybrid Laminar Flow
Control applications, in Notes on Numerical Fluid Mechanics and Multidisciplinary Design, vol. 142. Springer, Berlin (2019)

19. Ocaña, R., Soriano, C., Esmoris, J., Sanchez, R.: Fiber laser based single pulse drilling for production of perforated titanium sheets for HLFC structures. J. Laser Micro/Nanoengin. 14(1), 54-58 (2019)

20. Horn, M., Seitz, A., Schneider, M.: Novel tailored skin single duct concept for the HLFC fin application. In: 7th EUCASS, Milan (2017)

21. Horn, M., Seitz, A.: Cost-effective HLFC design concept for transport aircraft. In: DLRK 2019, Darmstadt, Germany (2019)

Publisher's Note Springer Nature remains neutral with regard to jurisdictional claims in published maps and institutional affiliations. 